\title{
Comparison of the incorporation of orally administered DHA into plasma, erythrocyte and cheek cell glycerophospholipids
}

\author{
Mario Klingler, Sabrina Klem, Hans Demmelmair and Berthold Koletzko* \\ Division of Metabolic and Nutritional Medicine, University of Munich Medical Center, Dr. von Hauner Children's Hospital, \\ Lindwurmstrasse 4, 80337 Munich, Germany
}

(Submitted 23 January 2012 - Final revision received 25 April 2012 - Accepted 29 April 2012 - First published online 3 July 2012)

\begin{abstract}
Adequate intake of $n$-3 fatty acids plays an important role in human health. The analysis of various blood lipids is used as a measure of fatty acid status in humans. Cheek cell phospholipids (PL) have also been proposed as biological markers, but are rarely used in clinical studies due to limitations in sample quality and quantity. An improved method for the analysis of cheek cell glycerophospholipid fatty acids is applied in a $29 \mathrm{~d}$ supplementation trial with $510 \mathrm{mg}$ DHA daily. The DHA increases in cheek cell, plasma and erythrocyte glycerophospholipids are compared. High correlations are shown for glycerophospholipid DHA between cheek cells and plasma $(r 0 \cdot 88)$ and erythrocytes $(r 0.76)$ before study commencement. After the daily supplementation of DHA, the half-maximal glycerophospholipid DHA level is reached after about $4 \mathrm{~d}$ in plasma, $6 \mathrm{~d}$ in erythrocytes and $10 \mathrm{~d}$ in cheek cells. The mean DHA increase (mol\%) relative to baseline was most prominent in plasma (186\%), followed by cheek cells (180\%) and erythrocytes (130\%). Considering a lag phase of about $5 \mathrm{~d}$, cheek cells reflect short-term changes in dietary fat uptake. Based on the data of the present study, they can be used alternatively to plasma and erythrocyte PL as non-invasive $n-3$ fatty acid status markers.
\end{abstract}

Key words: Cheek cells: DHA: Glycerophospholipids: Fatty acids

Adequate intake of $n-3$ long-chain PUFA, such as DHA and EPA, plays an important role in human health ${ }^{(1)}$. High DHA and EPA levels in blood lipids have been associated with improved infantile development, lower risk of CHD, lower incidence of cancer and avoidance of mental diseases ${ }^{(1)}$.

A modest increase in DHA and EPA uptake $(<300 \mathrm{mg} / \mathrm{d})$ can rapidly alter the fatty acid composition of blood lipids ${ }^{(2)}$. The incorporation of EPA and DHA into individual blood lipid fractions is time- and dose-dependent and differs between $n-3$ fatty acids ${ }^{(3)}$. The quantity of administered $n-3$ fatty acids determines total changes in tissues ${ }^{(4-6)}$. Plasma phospholipids (PL) or cholesteryl esters reach $n-3$ fatty acid equilibrium within 2 weeks, erythrocytes after approximately $120 \mathrm{~d}$ and adipose tissues after $1-2$ years $^{(6,7)}$. In most biological compartments, changes of EPA levels occur earlier and are more pronounced than changes of $\mathrm{DHA}^{(4-6,8)}$. This might be related to different affinities of EPA and DHA to lecithincholesterol acyltransferase ${ }^{(9)}$, different clearance rates of both $n$-3 fatty acids from plasma to adipose tissue ${ }^{(8)}$ or the displacement of DHA by EPA in plasma $\mathrm{PL}^{(7)}$. Moreover, the conversion of EPA to DHA is very limited ${ }^{(10)}$, whereas retroconversion of DHA to EPA was observed after DHA supplementation $^{(11)}$.
Strong correlations exist for EPA and DHA percentages between plasma and erythrocyte lipids ${ }^{(7,12)}$ and other tissues, such as cardiac tissue ${ }^{(13)}$, brain cortex $^{(14)}$ and cheek cell glycerophospholipids (GPL) ${ }^{(15)}$. Correlations of $n-3$ longchain-PUFA contents between adipose tissue and blood lipids are low or absent ${ }^{(16,17)}$. While the fatty acid analysis of blood lipids offers a measure for the fatty acid intake over the last few weeks, the analysis of subcutaneous fat reflects long-term fat intake ${ }^{(18)}$. Plasma PL or cholesteryl esters, erythrocyte PL, whole blood or plasma total lipids and adipose tissue are the preferred markers for $n$ - 3 fatty acid status in humans since $n-3$ long-chain-PUFA contents of these tissues are strongly correlated with dietary fat intake ${ }^{(19)}$.

Cheek cell PL have also been recommended as a biological marker for dietary fatty acid intake ${ }^{(20)}$, but they have rarely been used in clinical studies. This might be related to insecure sample quality and quantity and additionally required sample handling procedures ${ }^{(13)}$. On the other hand, sampling of cheek cells is less invasive than blood or adipose tissue sampling and therefore better accepted, particularly when applied in infants or children. Recently, we developed a robust method for the analysis of cheek cell GPL fatty acids, which requires only minimal sample amounts ${ }^{(15)}$.

Abbreviations: ARA, arachidonic acid; FAME, fatty acid methyl ester; GPL, glycerophospholipids; PL, phospholipids. 
This method has been applied in a 29d DHA supplementation trial. The supplement did not provide appreciable amounts of $n-3$ fatty acids other than DHA to avoid influences of these fatty acids on DHA incorporation into the studied compartments. The aims of the present study were the comparison of the time course of DHA incorporation into cheek cell, plasma and erythrocyte GPL, and the determination of the correlation of DHA between these tissues. The results of this study will show whether cheek cells reflect short-term or long-term changes in dietary fat intake and may underpin the suitability of cheek cells as a fatty acid status marker.

\section{Materials and methods}

\section{Subjects}

A total of thirteen volunteers were recruited for a supplementation study with DHA. Towards this, seven healthy females and six males between 20 and 40 years of age with a BMI of $20-25 \mathrm{~kg} / \mathrm{m}^{2}$ were invited. Participants ought not to have taken $n$-3 long-chain-PUFA supplements or medication assumed to interfere with the lipid metabolism 3 months before the start of the study. Further exclusion criteria were pregnancy, fatty fish consumption more than once per week, a weight reduction diet 4 weeks before study commencement and the abuse of alcohol or drugs.

The present study was conducted according to the guidelines laid down in the Declaration of Helsinki and all procedures involving human subjects were approved by the Ethical Committee of the University of Munich Medical Center (034-10). Written informed consent was obtained from all subjects before study commencement. The trial was registered at ClincialTrials.gov (NCT01192269).

\section{Experimental design and supplements}

The study consisted of a 2 -week baseline period followed by a $29 \mathrm{~d}$ intervention period and included clinical examinations at the beginning and the end of the study. Blood and cheek cells were sampled eleven times during the trial, on days -14 , 0 (start of intervention), 1, 2, 3, 4, 9, 14, 18, 24 and 29 (end of intervention). The study supplement consisted of a $950 \mu \mathrm{l}$ DHASCO $^{\circledR}$-S microalgae oil capsule (Martek Biosciences) containing $510 \mathrm{mg}$ DHA (Table 1). The content of EPA and other $n$-3 fatty acids was negligible ( $<0 \cdot 4 \%)$. Over the first $5 \mathrm{~d}$, capsules were administered directly after blood and cheek cell sampling. The capsules for the remaining intervention period were handed out at day 5 , and the participants were asked to take one capsule daily with breakfast and to record the time of consumption. Capsule counts were conducted at the end of the study.

\section{Glycerophospholipid fatty acid analysis of erythrocyte, cheek cell and plasma lipids}

The analysis of erythrocytes was conducted with a modified method for plasma GPL analysis ${ }^{(21)}$. Briefly, after an overnight fast, venous blood was collected into $7.5 \mathrm{ml}$ EDTA Monovettes
Table 1. Selected fatty acids of the study supplement $(950 \mu$ l capsule) according to the manufacturer

\begin{tabular}{lc}
\hline Fatty acid & $\% \mathrm{w} / \mathrm{w}$ \\
\hline $\mathrm{C} 14: 0$ & $11 \cdot 3$ \\
$\mathrm{C} 16: 0$ & $6 \cdot 0$ \\
$\mathrm{C} 18: 0$ & $0 \cdot 2$ \\
$\mathrm{C} 18: 1$ & $9 \cdot 6$ \\
$\mathrm{C} 18: 2 n-6$ & $0 \cdot 2$ \\
$\mathrm{C} 20: 4 n-6$ & $\mathrm{ND}$ \\
$\mathrm{C} 22: 5 n-6$ & $<0 \cdot 1$ \\
$\mathrm{C} 18: 3 n-3$ & $0 \cdot 3$ \\
C20:5n-3 & $<0 \cdot 1$ \\
$\mathrm{C} 22: 6 n-3$ & $59 \cdot 8$ \\
\hline
\end{tabular}

ND, not detected.

(Sarstedt) and directly placed on ice. Cooled samples were centrifuged $\left(1000 \mathrm{~g}, 10 \mathrm{~min}, 4^{\circ} \mathrm{C}\right)$ within $2 \mathrm{~h}$ after sampling. Plasma was separated, the buffy-coat was discarded, and remaining blood cells were washed three times with saline (0.9\% $\mathrm{NaCl})$.

A volume of $100 \mu \mathrm{l}$ erythrocytes was haemolysed by the addition of $100 \mu \mathrm{l}$ water; thereafter, $1300 \mu \mathrm{l}$ methanol plus $100 \mu \mathrm{l}$ internal standard (14.6 mg dipentadecanolyl-snglycero-phosphocholine, phosphatidylcholine 15:0, in $100 \mathrm{ml}$ methanol; Sigma Aldrich) were added during continuous shaking. The suspension was kept in an ultrasound water bath $(40 \mathrm{kHz}, 120 \mathrm{~W})$ for $5 \mathrm{~min}$. Precipitated proteins were separated by centrifugation $\left(3030 \mathrm{~g}, 10 \mathrm{~min}, 4^{\circ} \mathrm{C}\right)$, and the methanolic supernatant containing polar lipids was transferred into a small brown glass. Then, $50 \mu \mathrm{l}$ of sodium methoxide solution ( $25 \mathrm{wt} \%$ in methanol; Sigma Aldrich) were added to synthesise fatty acid methyl esters (FAME) from erythrocyte GPL at room temperature. After $4 \mathrm{~min}$, the reaction was stopped with $150 \mu \mathrm{l} 3 \mathrm{M}$-methanolic $\mathrm{HCl}$ (Sigma Aldrich). FAME were extracted twice into $600 \mu$ l hexane, the extracts were combined, hexane was evaporated under a continuous flow of $\mathrm{N}_{2}$, and the FAME were re-dissolved in $40 \mu \mathrm{l}$ hexane (containing $2 \mathrm{~g} / \mathrm{l}$ butylated hydroxytoluene). Samples were stored at $-20^{\circ} \mathrm{C}$ until GC analysis.

The analysis of GPL fatty acids from cheek cells and plasma required a slightly different sample preparation and was performed as recently described ${ }^{(15,21)}$. Briefly, cheek cells were collected with an endocervical brush and additional mouth rinse. Cheek cells were isolated by centrifugation before they were suspended in $1400 \mu \mathrm{l}$ methanol including phosphatidylcholine 15:0 as internal standard. The methanolic cell suspension was treated with ultrasound for $20 \mathrm{~min}$ and the precipitated proteins were removed by centrifugation. FAME synthesis and extraction were performed as described previously. The analysis of plasma GPL did not require sample pre-treatment. Methanol and internal standard were added directly to plasma for protein precipitation.

FAME were quantified by GC with flame ionisation detection (Agilent 5890 series II), using a $25 \mathrm{~m} \times 0.22 \mathrm{~mm}$ (inner diameter) BPX70 column (SGE). Injection temperature was set to $250^{\circ} \mathrm{C}$, the split ratio was $1 / 30$ and He was used as the carrier gas. The oven temperature was programmed to rise from 150 to $180^{\circ} \mathrm{C}$ at $2.5^{\circ} \mathrm{C} / \mathrm{min}$, followed by $1.5^{\circ} \mathrm{C} / \mathrm{min}$ to 
a final temperature of $200^{\circ} \mathrm{C}$, which was held for $1 \mathrm{~min}$. The pressure program started at $0.9 \mathrm{bar}$, and pressure increased by $0.02 \mathrm{bar} / \mathrm{min}$ to $1.2 \mathrm{bar}, 0.05 \mathrm{bar} / \mathrm{min}$ to $1.5 \mathrm{bar}$, and $0 \cdot 1 \mathrm{bar} / \mathrm{min}$ to a final pressure of $2 \cdot 0 \mathrm{bar}$. This pressure was held until the temperature program was completed ${ }^{(21)}$.

FAME were identified by comparison with a FAME standard mixture (GLC-569B, Nu-Check Prep, Inc.). All FAME response relative to pentadecanoic acid methyl ester (internal standard) was determined using GLC-85 (Nu-Check Prep, Inc.) as external standard. EZChrom Elite (version 3.1.7, Agilent) was used for peak integration.

\section{Dietary records}

Participants recorded their total food and beverage consumption on three consecutive days including one weekend day a week before the start of the intervention period. Nutrient intakes were calculated using PRODI (version 4.5 LE, Nutri-Science), which is based on the nutrient data bank of Souci-Fachmann-Kraut (version 2000) and the 'Bundeslebensmittelschlüssel' (version 2.3).

\section{Mathematical modelling and statistical analysis}

Curves of averaged DHA percentage increases $(y)$ of plasma, erythrocyte and cheek cell GPL were fitted according to the least square using OriginPro, version 8.5 software (originLab), by varying the parameters $a, b$ and $c$ of the equation

$$
y=a \times\left(1-e^{-b x}\right)^{c}
$$

where $x$ is the time in $\mathrm{d}$ since the onset of supplementation, and $a, b$ and $c$ are constants. The parameter $a$ represents the upper limit of the DHA percentage increase, which is approached with infinitive time $(x)$, while parameters $b$ and $c$ define the shape of the exponential increase. With $c=1$, this equation was used by Katan et $a l^{(6)}$ to model changes of EPA and DHA in cholesterol esters, erythrocytes and adipose tissue during fish oil supplementation. The time of the half-maximal DHA incorporation $t_{1 / 2}$ can be calculated as $\mathrm{DHA} t_{1 / 2}=-1 / b \times \ln \left(1-2^{-1 / c}\right)$.

Statistical analysis was performed using IBM SPSS Statistics for Windows, version 19.0.0.1 (IBM). Relative fatty acid contents (mol\%) are given as mean and standard deviation based on twenty detected cis-fatty acids with chain lengths between 14 and 24 carbon atoms ${ }^{(21)}$. Changes from baseline to day 29 were expressed as mean difference and 95\% CI, significance of differences was evaluated using paired $t$ tests. Correlation coefficients between compartments at baseline were evaluated according to Pearson. $P$ values $<0.05$ were considered as statistically significant.

\section{Results}

\section{Baseline characteristics and nutrient intake}

The compliance of the subjects was very good, and twelve of the thirteen participants followed exactly the study protocol. However, one participant consumed twenty-eight instead of twenty-nine capsules. This resulted in a DHA intake of about $96 \%$ of the planned dose; therefore this subject was not excluded from the study.

Baseline characteristics of the study subjects and their average nutrient intake are presented in Table 2 . The characteristics described did not change during the study (data not shown). No adverse effects were reported during the intervention period.

\section{Plasma, erythrocyte and cheek cell glycerophospholipid fatty acid compositions}

Table 3 shows the GPL fatty acid compositions of plasma, erythrocytes and cheek cells, determined before (averaged fatty acid baseline values of day -14 and day 0) and after the supplementation period (day 29). The majority of individual GPL fatty acid proportions differed significantly between the three compartments. Palmitic-, stearic-, oleic-, linoleicand arachidonic acids (ARA) were the predominant fatty acids in plasma and erythrocytes, averaging 88.0 (SD 1.4) and 85.0 (SD 1.2$) \mathrm{mol} \%$, respectively. In cheek cells, palmitic-, stearic-, oleic-, linoleic- and palmitoleic acids presented the major fatty acids comprising 86.3 (SD 1.0) mol\%. Erythrocytes contained the highest levels of ARA and DHA averaging $15 \cdot 2$ (SD 1.6) and 4.3 (SD 0.8) $\mathrm{mol} \%$, followed by plasma with $10 \cdot 1$ (SD 1.5) and $2 \cdot 7(\mathrm{SD} 0 \cdot 5) \mathrm{mol} \%$ and cheek cells with $3 \cdot 2$ (SD 0.6$)$ and $0 \cdot 7$ (SD $0 \cdot 1)$ mol\%, respectively.

Table 2. Characteristics of the study participants $(n$ 13) and their nutrient intake at baseline

(Mean values and standard deviations)

\begin{tabular}{lcc}
\hline & Mean & SD \\
\hline Characteristics & & \\
Age (years) & $25 \cdot 8$ & $2 \cdot 7$ \\
BMI (kg/m ${ }^{2}$ ) & $21 \cdot 9$ & $1 \cdot 6$ \\
Body fat (\%) & $20 \cdot 9$ & $8 \cdot 2$ \\
Waist circumferrence (cm) & $81 \cdot 7$ & $5 \cdot 7$ \\
Blood pressure & & \\
Systolic (mmHg) & 128 & 15 \\
Diastolic (mmHg) & 70 & 6 \\
Heart rate (beats/min) & 69 & 7 \\
GT (U/l) & 16 & 5 \\
GPT (U/l) & 16 & 5 \\
GOT (U/l) & 20 & 4 \\
Cholesterol (mg/l) & 1640 & 190 \\
TAG (mg/l) & 830 & 260 \\
CRP (high sensitivity) (mg/l) & 2 & 4 \\
LDL (mg/l) & 800 & 200 \\
HDL (mg/l) & 670 & 90 \\
LDL:HDL ratio & $1 \cdot 2$ & $0 \cdot 3$ \\
Nutrient intake & & \\
Energy (MJ/d) & $9 \cdot 1$ & $1 \cdot 4$ \\
Protein (percentage of energy) & $14 \cdot 8$ & $2 \cdot 9$ \\
Carbohydrates (percentage of energy) & $49 \cdot 6$ & $9 \cdot 7$ \\
Total fat (percentage of energy) & $33 \cdot 8$ & $11 \cdot 3$ \\
SFA (percentage of energy) & $15 \cdot 1$ & $4 \cdot 9$ \\
MUFA (percentage of energy) & $11 \cdot 8$ & $3 \cdot 3$ \\
PUFA (percentage of energy) & $4 \cdot 9$ & $1 \cdot 8$ \\
DHA (mg/d) & 79 & 51 \\
EPA (mg/d) & 43 & 28 \\
\hline
\end{tabular}

GT, glutamyl transpeptidase; GPT, glutamic pyruvic transaminase; GOT, glutanic oxaloacetic transaminase; CRP, C-reactive protein. 
Table 3. Fatty acid compositions ( $\mathrm{mol} \%$ ) of plasma, erythrocytes $†$ and cheek cells at baseline

(Mean values, standard deviations, mean difference and $95 \%$ confidence intervals; $n 13$ )

\begin{tabular}{|c|c|c|c|c|c|c|c|c|c|c|c|c|}
\hline & \multicolumn{4}{|c|}{ Plasma } & \multicolumn{4}{|c|}{ Erythrocytes } & \multicolumn{4}{|c|}{ Cheek Cells } \\
\hline & \multicolumn{2}{|c|}{ Baseline } & \multirow[b]{2}{*}{$\begin{array}{l}\text { Change at } \\
\text { day } 29\end{array}$} & \multirow[b]{2}{*}{$95 \% \mathrm{Cl}$} & \multicolumn{2}{|c|}{ Baseline } & \multirow[b]{2}{*}{$\begin{array}{c}\text { Change at } \\
\text { day } 29\end{array}$} & \multirow[b]{2}{*}{$95 \% \mathrm{Cl}$} & \multicolumn{2}{|c|}{ Baseline } & \multirow[b]{2}{*}{$\begin{array}{c}\text { Change at } \\
\text { day } 29\end{array}$} & \multirow[b]{2}{*}{$95 \% \mathrm{Cl}$} \\
\hline & Mean & SD & & & Mean & SD & & & Mean & SD & & \\
\hline C16:0 & $31 \cdot 16$ & 1.54 & 0.90 & $0.45,1.35^{\star \star}$ & 24.99 & $2 \cdot 15$ & 0.59 & $-0.80,1.99$ & $16 \cdot 55$ & 1.81 & -0.09 & $-0.85,0.68$ \\
\hline C18:0 & $12 \cdot 29$ & 1.00 & -0.15 & $-0.53,0.23$ & 17.84 & 0.55 & -0.32 & $-0.63,-0.01^{*}$ & $15 \cdot 31$ & 1.43 & -0.30 & $-1.05,0.46$ \\
\hline C16:1n-7 & 0.94 & 0.46 & -0.06 & $-0.16,0.04$ & 0.41 & 0.19 & -0.02 & $-0.07,0.02$ & 7.06 & $1 \cdot 13$ & -0.31 & $-0.57,-0.05^{\star}$ \\
\hline C18: $1 n-7$ & 1.52 & 0.17 & 0.11 & $0.03,0.20^{*}$ & 1.35 & 0.13 & -0.01 & $-0.05,0.03$ & 4.68 & 0.61 & 0.14 & $-0.14,0.42$ \\
\hline C18: $1 n-9$ & 11.68 & 1.30 & -0.22 & $-0.75,0.31$ & 15.02 & 0.78 & 0.09 & $-0.26,0.44$ & 30.06 & 2.04 & -0.23 & $-1 \cdot 10,0.65$ \\
\hline C18:2n-6 & $22 \cdot 80$ & $2 \cdot 70$ & -1.35 & $-2.47,-0.23^{\star}$ & $12 \cdot 02$ & 1.22 & -0.08 & $-0.58,0.42$ & $17 \cdot 32$ & 1.77 & 0.56 & $-0.28,1.39$ \\
\hline C18: $3 n-6$ & 0.16 & 0.07 & -0.06 & $-0.10,-0.03^{\star \star}$ & 0.08 & 0.03 & -0.04 & $-0.06,-0.02^{\star \star \star}$ & 0.20 & 0.08 & 0.02 & $-0.04,0.07$ \\
\hline $\mathrm{C} 20: 3 n-6$ & 2.93 & 0.75 & -0.23 & $-0.47,0.01$ & 1.82 & 0.36 & -0.12 & $-0.18,-0.07^{\star \star \star}$ & 1.42 & 0.35 & -0.05 & $-0.15,0.05$ \\
\hline $\mathrm{C} 20: 4 n-6$ & 10.07 & 1.49 & -1.01 & $-1.52,-0.49^{\star *}$ & $15 \cdot 16$ & 1.59 & -0.76 & $-1.78,0.25$ & $3 \cdot 20$ & 0.64 & -0.31 & $-0.67,0.04$ \\
\hline C22: $5 n-6$ & 0.28 & 0.10 & $-0 \cdot 10$ & $-0.13,-0.06^{\star \star \star}$ & 0.71 & 0.15 & -0.09 & $-0.12,-0.05^{\star \star \star}$ & 0.07 & 0.03 & -0.01 & $-0.02,0.00$ \\
\hline $\mathrm{C} 18: 3 n-3$ & 0.28 & 0.13 & -0.02 & $-0.07,0.03$ & 0.15 & 0.04 & 0.00 & $-0.01,0.01$ & 0.24 & 0.12 & 0.06 & $-0.09,0.20$ \\
\hline $\mathrm{C} 20: 5 n-3$ & 0.76 & 0.53 & -0.01 & $-0.22,0.21$ & 0.55 & 0.23 & 0.01 & $-0.05,0.06$ & 0.21 & 0.11 & 0.04 & $-0.02,0.10$ \\
\hline C22: $5 n-3$ & 0.73 & 0.22 & -0.21 & $-0.27,-0.14^{\star \star \star}$ & 1.85 & 0.36 & -0.16 & $-0.36,0.03$ & 0.23 & 0.08 & -0.04 & $-0.08,0.00$ \\
\hline $\mathrm{C} 22: 6 n-3$ & 2.69 & 0.52 & $2 \cdot 20$ & $1 \cdot 66,2 \cdot 73^{\star \star \star}$ & 4.28 & 0.76 & 1.18 & $0.89,1.46^{\star \star \star}$ & 0.69 & 0.14 & 0.54 & $0.43,0.66^{\star \star \star}$ \\
\hline
\end{tabular}

Significant changes of individual fatty acid contents during intervention are indicated as ${ }^{\star} P<0.05,{ }^{\star \star} P<0.01$ or ${ }^{\star \star \star} P<0.001$; one-sample $t$ test. $\dagger$ Erythrocyte values for samples stored for 8 months have been reported elsewhere ${ }^{(34)}$.

The additional DHA intake of $510 \mathrm{mg} / \mathrm{d}$ significantly increased the DHA content in all three compartments, which was by $2.20 \mathrm{~mol} \%(95 \%$ CI $1.66,2.73 ; P<0.001)$ in plasma, $1.18 \mathrm{~mol} \%(95 \% \mathrm{CI} 0.89,1.46 ; P<0.001)$ in erythrocytes and $0.54 \mathrm{~mol} \%(95 \% \mathrm{CI} 0.43,0.66 ; P<0.001)$ in cheek cells at the end of the study. ARA proportions decreased during the same period, but differences were only in plasma statistically significant $(-1.01 \mathrm{~mol} \% ; 95 \%$ CI $-1.52,-0.49 ; P<0.002)$. Proportions of plasma linoleic acid decreased during the intervention period $(-1.35 \mathrm{~mol} \% ; 95 \%$ CI $-2.47, \quad-0.23$; $P=0.022$ ), but this change was not observed in erythrocytes or cheek cells. EPA contents were not significantly affected by DHA supplementation. The study was not adequately powered to determine reliably changes in fatty acids other than DHA; thus the changes and correlations between percentages in different compartments were analysed on an explorative basis only.

Correlation coefficients were computed between individual fatty acids of all three compartments at baseline (Table 4). Major cheek cell fatty acids, such as oleic- and linoleic acid did not correlate with erythrocytes and plasma, while significant correlations were found for palmitic $(r$ 0.64) and stearic acids $(r$. 70). High correlations were found for DHA contents between cheek cells and erythrocytes as well as cheek cells and plasma ( $r \quad 0.88$ and 0.76 , respectively), and for EPA between the same compartments $(r 0.79$ and $r 0.66$, respectively). The sum of both $n$ - 3 fatty acids DHA and EPA was also highly correlated ( $r 0.87$ and $r 0.72$, respectively). Correlations for ARA were only found between cheek cells and plasma ( $r$ 0.65), but not between other compartments.

Table 4. Correlation coefficients of individual glycerophospholipid fatty acids between cheek cells, erythrocytes and plasma before DHA supplementation

\begin{tabular}{lrlllll}
\hline Fatty acid & $R$ & $P$ & $R$ & $P$ & $R$ & $P$ \\
\hline C16:0 & 0.32 & NS & 0.64 & 0.026 & 0.33 & NS \\
C18:0 & 0.33 & NS & 0.70 & 0.010 & 0.59 & 0.04 \\
C16: $1 n-7$ & -0.47 & NS & -0.37 & NS & 0.84 & $<0.001$ \\
C18: $1 n-7$ & 0.14 & NS & 0.15 & NS & 0.23 & NS \\
C18: $1 n-9$ & 0.10 & NS & 0.40 & NS & 0.26 & NS \\
C18:2n-6 & -0.05 & NS & -0.04 & NS & 0.71 & $<0.01$ \\
C18:3n-6 & 0.57 & NS $(0.05)$ & 0.50 & $<0.001$ & 0.86 & $<0.001$ \\
C20:3n-6 & 0.65 & 0.020 & 0.74 & $<0.001$ & 0.78 & $<0.01$ \\
C20 $: 4 n-6$ & 0.17 & NS & 0.65 & 0.01 & 0.49 & NS \\
C22: $5 n-6$ & 0.70 & 0.010 & 0.78 & $<0.001$ & 0.94 & $<0.001$ \\
C18:3n-3 & 0.13 & NS & 0.11 & NS & 0.72 & $<0.01$ \\
C20:5n-3 & 0.79 & $<0.01$ & 0.66 & NS & 0.88 & $<0.001$ \\
C22: $: 5 n-3$ & 0.39 & NS & 0.85 & NS & 0.59 & 0.04 \\
C22 $: 6 n-3$ & 0.88 & $<0.001$ & 0.76 & $<0.001$ & 0.89 & $<0.001$ \\
EPA + DHA & 0.87 & $<0.001$ & 0.72 & $<0.01$ & 0.88 & $<0.001$ \\
\hline
\end{tabular}

NS, $P>0.05$, Pearson's correlation coefficient. 
Most of the fatty acids in plasma and erythrocytes were highly correlated, except for palmitic acid, oleic acid, vaccenic acid, and ARA. Correlations calculated for EPA, DHA and EPA + DHA were similar to those of cheek cells and erythrocytes.

At the end of the study, correlations for DHA levels between cheek cells and plasma $(r 0 \cdot 60, P=0 \cdot 03)$ or erythrocytes $(r 0 \cdot 77$, $P=0.002)$ tended to be lower, whereas DHA levels did not correlate any more between plasma and erythrocytes $(r 0 \cdot 353, \mathrm{NS})$.

\section{Incorporation of DHA in plasma, erythrocytes and cheek cells}

Fig. 1 shows changes of DHA mol\% in plasma, erythrocyte and cheek cell GPL over the course of supplementation. The mean DHA increase $(\mathrm{mol} \%)$ relative to the baseline level was most prominent in plasma (186\%), followed by cheek cells (180\%) and erythrocytes (130\%).

The parameter $a$, representing the estimated maximal increase of $\mathrm{DHA}_{\infty}$, was 2.25, 1.09 and 0.68 for plasma, erythrocytes and cheek cells. The parameters $b$ and $c$ describe the course of the increase over time with 0.07 and 0.52 for plasma, 0.10 and 0.97 for erythrocytes, and 0.10 and 1.68 for cheek cells. The parameters are based on the collected data points until day 29 and thus may not reflect processes mostly effective during longer intervention periods. Solving the equation used for time until half of the expected maximal increase is reached (DHA $t_{1 / 2}$ ), yielded $4.4 \mathrm{~d}$ for plasma, $6.4 \mathrm{~d}$ for erythrocytes and $10 \cdot 4 \mathrm{~d}$ for cheek cells.

\section{Discussion}

This is the first study evaluating the incorporation rate of DHA into cheek cell GPL in comparison to plasma and erythrocyte GPL. High correlations are found for DHA between all three compartments. In our $29 \mathrm{~d}$ supplementation trial $(510 \mathrm{mg}$ DHA/d), a half-maximal GPL DHA level is reached after about $4 \mathrm{~d}$ in plasma, $6 \mathrm{~d}$ in erythrocytes and $10 \mathrm{~d}$ in cheek

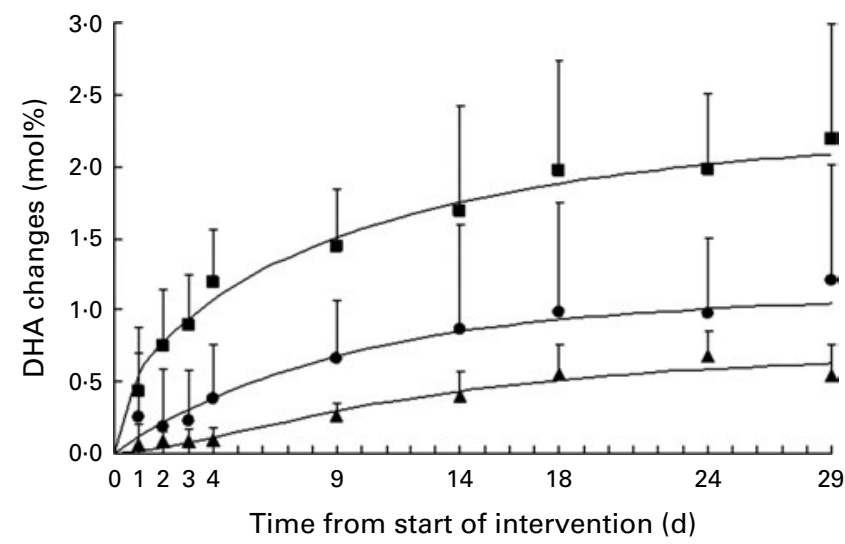

Fig. 1. DHA changes from baseline in different compartments of subjects supplemented with $510 \mathrm{mg}$ DHA daily over $29 \mathrm{~d}$. Values are means with standard deviations represented by vertical bars. Curves were fitted to $y=a \times\left(1-e^{-b x}\right)^{c}$ resulting in the following parameters for plasma (ם): $a=2.25, b=0.07, c=0.52$; erythrocytes $(\bullet): a=1.09, b=0.10, c=0.97$ and cheek cells $(\mathbf{\Lambda}): a=0.68, b=0.10, c=1.68$. cells. The relative response to DHA supplementation is highest in plasma and cheek cells. Our findings support the use of cheek cells as a $n-3$ fatty acid status marker.

The distribution of total GPL fatty acids in cheek cell and plasma determined in our study cohort is comparable to other studies ${ }^{(15,21,22)}$. Data for fatty acid contents of total GPL in erythrocytes are not available. However, our results can be compared to those reported for erythrocyte total fatty acids $^{(12)}$, although differences for some individual fatty acids are indicated. This might be related to the contribution of sphingomyelin fatty acids to erythrocyte total fatty acids. Sphingomyelin contains high amounts of palmitic acid and only traces of $n-3$ fatty acids ${ }^{(23)}$. This is reflected in the respective patterns of erythrocyte total and GPL fatty acids.

At the start of the study, GPL DHA proportions of cheek cells in our subjects averaged $0.7 \mathrm{~mol} \%(0.8 \mathrm{wt} \%)$, which is comparable to DHA levels in cheek cell PL reported for breastfed infants ${ }^{(24,25)}$, elderly people ${ }^{(13)}$ and cheek cell GPL in adults ${ }^{(15)}$. In comparison to plasma and erythrocytes, the DHA content of cheek cells is approximately one-third. This may limit the validity of cheek cell GPL as a fatty acid status marker, but it has been shown that changes of $n-3$ and $n-6$ fatty acid uptakes are reflected in cheek cell lipids similarly to erythrocytes or plasma ${ }^{(13,24-26)}$. Moreover, the outcome of our supplementation study shows that the relative DHA increase in cheek cells is comparable to that in plasma, which is in agreement with DHA changes reported for plasma (104 wt\%) and cheek cell PL (95 wt \%) in patients receiving $400 \mathrm{mg}$ DHA per $\mathrm{d}$ over a period of 6 months ${ }^{(13)}$.

Little is known about DHA incorporation into cheek cells. The oral mucosa is an avascular stratified squamous epithelium $^{(27)}$. Cells of the base membrane are continuously renewed by mitosis, and migrate through the epithelium to the surface ${ }^{(28)}$. The nutrient and metabolite content of the outer epithelium layer is determined by cell migration and to a smaller extent by diffusion ${ }^{(27)}$. The estimated renewal time of buccal cheek cells is $5-8 \mathrm{~d}^{(29,30)}$. These characteristics of the oral mucosa suggest that DHA changes in the analysed outer epithelial layer can be expected not earlier than $5 \mathrm{~d}$ after the onset of supplementation. Such a delay is observed in our study, although an increase is indicated after $1 \mathrm{~d}$, which might be explained by passive transport mechanisms. However, we have no information about the exact time when the increase took place, as samples between day 5 and day 8 were not collected. Considering the lag-phase of at least $5 \mathrm{~d}$, half-maximal DHA levels are reached quickly, which is comparable to plasma. DHA contents in cheek cells do not further increase after $24 \mathrm{~d}$, suggesting that DHA equilibrium is reached at about this time. These data indicate that cheek cells reflect short-term changes of the dietary $n-3$ fatty acid pattern; however, a delayed increase at the start of the intervention has to be considered.

Plasma and erythrocyte lipids are used as biological markers for dietary fat intake. Their $n-3$ and $n-6$ fatty acid contents are highly correlated ${ }^{(12)}$. Correlations described for cheek cells with other biological markers are mainly related to DHA, EPA and ARA. Strong correlations have been shown for DHA between cheek cell PL and plasma PL ( $r$ 0.83), erythrocyte 
total lipids $\left(\begin{array}{ll}r & 0.72\end{array}\right)^{(25)}$, plasma total lipids $\left(\begin{array}{ll}r & 0.61\end{array}\right)^{(24)}$ and

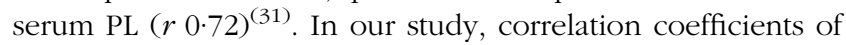
$r>0.75$ have been determined between DHA in cheek cell, plasma and erythrocyte GPL. Correlations between cheek cell and plasma EPA have been only reported in a single study $^{(31)}$, in which the $r$-value of 0.56 is similar to that in our study. Correlations of ARA levels between cheek cells and blood compartments have also already been determined, but results are inconsistent. Whereas ARA contents correlated between cheek cell and serum $\mathrm{PL}^{(31)}$, none or weak relationships were reported between cheek cell PL and plasma PL or erythrocyte total lipids ${ }^{(24,25)}$. No correlations have been found between ARA levels in plasma and erythrocyte total fatty acids $^{(32)}$. Our results confirm previous findings, where correlations were only indicated between cheek cells and plasma, but not between the other compartments.

The supplementation of DHA as an individual $n$ - 3 fatty acid was chosen to exclude the effects of other fatty acids on the incorporation of DHA into GPL. Consuming fish or fish oil capsules may result in different DHA levels than those observed in our study due to the competition of EPA and DHA for the sn-2 position of GPL. There was no control group without DHA supplementation included, and hence we cannot compare the intervention effects to a reference group. Systematic changes of fatty acid compositions during the study period cannot be excluded, but such changes are not expected during a 4-week period. An estimate for random variation was obtained by duplicate baseline measurements within 2 weeks before study start. In all compartments, differences for DHA percentages were small compared to those observed after supplementation (data not shown). Also, providing DHA only allows detecting changes in EPA related to retroconversion. Based on the EPA results, retroconversion did not take place during the supplementation period of $29 \mathrm{~d}$. We cannot exclude that with a prolonged intervention time a further increase in DHA proportions would have occurred in the three compartments. However, this seems unlikely as DHA in cheek cells derives from plasma lipids, and plasma DHA levels reach equilibrium within 1 month.

While the studied daily supplementation with $510 \mathrm{mg}$ DHA is clearly above the average habitual DHA intake in most countries $^{(33)}$, this dosage has frequently been applied in interventional studies to test DHA effects ${ }^{(2)}$. We tested only the kinetics of DHA incorporation following a change in intake from about $80 \mathrm{mg}$ DHA to $590 \mathrm{mg}$ per d. Nevertheless, we assume that with lower DHA intakes similar curves, with lower maximal changes, would be observed as for DHA supplementations up to $1 \mathrm{~g} / \mathrm{d}$ increases in plasma PL DHA percentages have been found to be proportional to intake increases ${ }^{(7)}$. On the other hand, a further increase of the supplementation dose leads to disproportional increases of DHA in plasma ${ }^{(7)}$ and kinetics will probably differ. In case of very low basal DHA levels and/or minute changes of DHA intakes, cheek cell GPL analysis might be disadvantageous compared to plasma or erythrocytes, as cheek cells contain less GPL DHA which may influence the relative error of measurements unfavourably.
In summary, after a lag-phase of a few days, cheek cells respond quickly to DHA supplementation. The relative increase over 4 weeks is comparable to plasma, although the proportion of DHA in cheek cells is small compared to plasma and erythrocytes. This indicates that cheek cells reflect short-term changes in dietary fatty acid composition. Furthermore, sampling of cheek cells is simple and applicable in a non-clinical environment. Based on the results of this study, cheek cell GPL are an alternative to plasma and erythrocyte PL as biological markers for $n-3$ fatty acid status, especially in $n-3$ fatty acid supplementation trials and studies, where blood sampling is difficult or not applicable.

\section{Acknowledgements}

The authors gratefully acknowledge the provision of the DHASCO ${ }^{\circledR}-S$ microalgae oil by Martek Biosciences. Furthermore, the authors thank Dr Claudia Matthies for her valuable support during the intervention trial and subsequent sample analysis. The present study was financially supported by the Federal Ministry of Education and Research (0315680B). B. K. is receiving a Freedom to Discover Award of the Bristol-Myers Squibb Foundation, New York, NY. The methods for the GPL FA analysis presented in this article are in patent pending status. M. K., H. D. and B. K. conceived and designed the experiments of the clinical study; M. K. and S. K. performed the experiments; M. K. and H. D. analysed the data. M. K., S. K., H. D. and B. K. wrote the paper and were responsible for the review and approval of the manuscript. The authors have no conflicts of interest to declare.

\section{References}

1. Riediger ND, Othman RA, Suh M, et al. (2009) A systemic review of the roles of $n-3$ fatty acids in health and disease. J Am Diet Assoc 109, 668-679.

2. Fekete K, Marosvolgyi T, Jakobik V, et al. (2009) Methods of assessment of $n-3$ long-chain polyunsaturated fatty acid status in humans: a systematic review. Am J Clin Nutr 89, 2070S-2084S.

3. Masson S, Latini R, Tacconi M, et al. (2007) Incorporation and washout of $n-3$ polyunsaturated fatty acids after diet supplementation in clinical studies. J Cardiovasc Med (Hagerstown) 8, Suppl. 1, S4-10.

4. Brown AJ, Pang E \& Roberts DC (1991) Persistent changes in the fatty acid composition of erythrocyte membranes after moderate intake of $n$-3 polyunsaturated fatty acids: study design implications. Am J Clin Nutr 54, 668-673.

5. Di Stasi D, Bernasconi R, Marchioli R, et al. (2004) Early modifications of fatty acid composition in plasma phospholipids, platelets and mononucleates of healthy volunteers after low doses of $n-3$ polyunsaturated fatty acids. Eur J Clin Pharmacol 60, 183-190.

6. Katan MB, Deslypere JP, van Birgelen AP, et al. (1997) Kinetics of the incorporation of dietary fatty acids into serum cholesteryl esters, erythrocyte membranes, and adipose tissue: an 18-month controlled study. J Lipid Res 38, 2012-2022.

7. Arterburn LM, Hall EB \& Oken H (2006) Distribution, interconversion, and dose response of $n-3$ fatty acids in humans. Am J Clin Nutr 83, 1467S-1476S. 
8. Zuijdgeest-van Leeuwen SD, Dagnelie PC, Rietveld T, et al. (1999) Incorporation and washout of orally administered $n$-3 fatty acid ethyl esters in different plasma lipid fractions. Br J Nutr 82, 481-488.

9. Subbaiah PV, Kaufman D \& Bagdade JD (1993) Incorporation of dietary $n-3$ fatty acids into molecular species of phosphatidyl choline and cholesteryl ester in normal human plasma. Am J Clin Nutr 58, 360-368.

10. Brenna JT, Salem N Jr, Sinclair AJ, et al. (2009) $\alpha$-Linolenic acid supplementation and conversion to $n-3$ long-chain polyunsaturated fatty acids in humans. Prostaglandins Leukot Essent Fatty Acids 80, 85-91.

11. Plourde M, Chouinard-Watkins R, Vandal M, et al. (2011) Plasma incorporation, apparent retroconversion and betaoxidation of 13C-docosahexaenoic acid in the elderly. Nutr Metab (Lond) 8, 5.

12. Geppert J, Kraft V, Demmelmair H, et al. (2005) Docosahexaenoic acid supplementation in vegetarians effectively increases omega-3 index: a randomized trial. Lipids 40, 807-814.

13. Harris WS, Sands SA, Windsor SL, et al. (2004) Omega-3 fatty acids in cardiac biopsies from heart transplantation patients: correlation with erythrocytes and response to supplementation. Circulation 110, 1645-1649.

14. Makrides M, Neumann M, Byard R, et al. (1994) Fatty acid composition of brain, retina, and erythrocytes in breastand formula-fed infants. Am J Clin Nutr 60, 189-194.

15. Klingler M, Demmelmair H, Koletzko B, et al. (2011) Fatty acid status determination by cheek cell sampling combined with methanol-based ultrasound extraction of glycerophospholipids. Lipids 46, 981-990.

16. Baylin A, Kim MK, Donovan-Palmer A, et al. (2005) Fasting whole blood as a biomarker of essential fatty acid intake in epidemiologic studies: comparison with adipose tissue and plasma. Am J Epidemiol 162, 373-381.

17. Ogura T, Takada H, Okuno M, et al. (2010) Fatty acid composition of plasma, erythrocytes and adipose: their correlations and effects of age and sex. Lipids 45, 137-144.

18. Arab L (2003) Biomarkers of fat and fatty acid intake. J Nutr 133, Suppl. 3, 925S-932S.

19. Hodson L, Skeaff CM \& Fielding BA (2008) Fatty acid composition of adipose tissue and blood in humans and its use as a biomarker of dietary intake. Prog Lipid Res 47, 348-380.

20. McMurchie EJ, Margetts BM, Beilin LJ, et al. (1984) Dietaryinduced changes in the fatty acid composition of human cheek cell phospholipids: correlation with changes in the dietary polyunsaturated/saturated fat ratio. Am J Clin Nutr 39, 975-980.

21. Glaser C, Demmelmair H \& Koletzko B (2010) High-throughput analysis of fatty acid composition of plasma glycerophospholipids. J Lipid Res 51, 216-221.

22. Glaser C, Demmelmair H, Sausenthaler S, et al. (2010) Fatty acid composition of serum glycerophospholipids in children. J Pediatr 157, 826-831, (e821).

23. Kornsteiner M, Singer I \& Elmadfa I (2008) Very low $n$-3 long-chain polyunsaturated fatty acid status in Austrian vegetarians and vegans. Ann Nutr Metab 52, 37-47.

24. Connor SL, Zhu N, Anderson GJ, et al. (2000) Cheek cell phospholipids in human infants: a marker of docosahexaenoic and arachidonic acids in the diet, plasma, and red blood cells. Am J Clin Nutr 71, 21-27.

25. Hoffman DR, Birch EE, Birch DG, et al. (1999) Fatty acid profile of buccal cheek cell phospholipids as an index for dietary intake of docosahexaenoic acid in preterm infants. Lipids 34, 337-342.

26. Hoffman DR \& Uauy R (1992) Essentiality of dietary omega 3 fatty acids for premature infants: plasma and red blood cell fatty acid composition. Lipids $\mathbf{2 7}, 886-895$.

27. Salamat-Miller N, Chittchang M \& Johnston TP (2005) The use of mucoadhesive polymers in buccal drug delivery. Adv Drug Deliv Rev 57, 1666-1691.

28. Hill MW (1984) Cell renewal in oral epithelia. In The Structure and Function of Oral Mucosa, pp. 53-81 [J Meyer, CA Squier and SJ Gerson, editors]. Oxford: Pergamon Press Ltd.

29. Gillespie GM (1969) Renewal of buccal epithelium. Oral Surg Oral Med Oral Pathol 27, 83-89.

30. Kaidbey KH \& Kurban AK (1971) Mitotic behaviour of the buccal mucosal epithelium in psoriasis. Br J Dermatol 85 , $162-166$.

31. Laitinen K, Sallinen J, Linderborg K, et al. (2006) Serum, cheek cell and breast milk fatty acid compositions in infants with atopic and non-atopic eczema. Clin Exp Allergy 36, 166-173.

32. Bailey-Hall E, Nelson EB \& Ryan AS (2008) Validation of a rapid measure of blood PUFA levels in humans. Lipids $\mathbf{4 3}$, 181-186.

33. Ian Givens D \& Gibbs RA (2008) Current intakes of EPA and DHA in European populations and the potential of animalderived foods to increase them. Proc Nutr Soc 67, 273-280.

34. Klem S, Klingler M, Demmelmair H, et al. (2012) Efficient and specific analysis of red blood cell glycerophospholipid fatty acid composition. PLoS One 7, e33874 